\title{
CARACTERIZAÇÃO DOS ENUNCIADOS DE UM ALUNO NÃO-FALANTE USUÁRIO DE RECURSO SUPLEMENTAR DE COMUNICAÇÃO DURANTE A CONSTRUÇÃO DE HISTÓRIAS
}

\author{
Characterization of THE STATEMENTS OF A NON-SPEAKING STUDENT \\ AUGMENTATIVE AND ALTERNATIVE COMMUNICATION RESOURCES USER DURING \\ STORY CONSTRUCTION
}

\author{
Nathália Silveira da GUARDA ${ }^{1}$ \\ Débora DELIBERATO²
}

\begin{abstract}
RESUMO: a narrativa pode conectar elementos diversos e, assim, promover a construção de sentenças verticais e horizontais, frente à mediação de interlocutor. Esta pesquisa visou analisar a extensão e a organização sintática dos enunciados de narrativas construídas por um aluno não-falante usuário de recurso suplementar de comunicação. Previamente à construção das narrativas, selecionadas de acordo com os centros de interesse, idade, grau de escolaridade e temáticas trabalhadas na escola do aluno, símbolos gráficos do Picture Communication Symbols eram confeccionados e adaptados para que, por meio destes e dos recursos verbais e não-verbais inerentes à atividade discursiva, a história pudesse ser contada, por acesso visual e auditivo, pelo interlocutor e recontada pelo aluno, após a estruturação e organização dos múltiplos signos em sentenças. Todas as interações foram filmadas e complementadas com anotações de um diário de registro contínuo. Após a análise das transcrições das fitas e das anotações do diário, foi possível determinar três estágios de unidades significativas: 1) Caracterização ou natureza dos elementos constituintes dos enunciados das narrativas em: a) objeto; b) símbolo gráfico; c) escrita; d) vocalização; e) gesto representativo; 2) Extensão dos enunciados das narrativas de 1 a 6 elementos, linearmente, e 7 ou mais elementos; 3) Organização sintática dos elementos constituintes das narrativas em sujeito, verbo e objeto isolados, em sentenças verticais, e associados, em sentenças horizontais. Ressaltou-se, assim, a ampliação e aprimoramento da organização e da estrutura sintática dos enunciados das narrativas construídas pelo aluno mediado pelo interlocutor.
\end{abstract}

PALAVRAS-CHAVE: educação especial; comunicação alternativa e suplementar; narração de histórias.

\begin{abstract}
: narratives can connect diverse elements and, thus, promote the construction of vertical and horizontal sentences, mediated by the interlocutor. This research aimed to analyze the extension and the syntactic organization of narrative statements constructed by a non-speaking student who used Augmentative and Alternative Communication devices. Graphic Symbols from Picture Communication Symbols were selected according to the child's range of interest, his age, schooling and the subject areas he was involved with in school, having been prepared and adapted to his needs, before the actual narrative construction. Using these pictograms as well as verbal and non-verbal resources that are part of the discursive mode, a story could be told by the communication partner, accessed through visual as well as auditory channels. After structuring and re-organizing the various signs into sentences, the student could retell the story. All interactions were filmed and complemented with notations in an ongoing journal registry. Analyzing the tape transcriptions and the journal notations enabled us to identify three significant unit stages: 1) Characterization or nature of the constituent elements of narrative statements in: a) the object; b) the graphic symbol; c) writing; d) vocalization; e) representative gesture; 2) Extension of the narrative statements from 1 to 6 elements in sequence and 7 or more elements; 3) Syntactic organization of the elements making up the narratives in a subject - verb - object structure, isolated in vertical sentences and associated in horizontal sentences. The results thus pointed to the broadening and improvement of the syntactic organization and structure of the narrative statements constructed by the student, mediated by the communication exchange partner.
\end{abstract}

KEYWORDS: special education; augmentative and alternative communication; story narration.

\footnotetext{
${ }^{1}$ Fonoaudióloga; aluna do Programa de Programa de Pós-Graduação em Educação da Unesp, Marília nathalia_fono@yahoo.com.br

${ }^{2}$ Docente do Departamento de Educação Especial e do Programa de Pós-Graduação em Educação da UNESP, Marília - delibera@marilia.unesp.br.
} 


\section{INTRODUÇÃo}

Consoante von Tetzchner (2003), o ensino e o uso de enunciados de múltiplos símbolos teriam recebido pouca atenção na literatura especializada e, conseqüentemente, no que tange à redução de estratégias favorecedoras do desenvolvimento sintático e semântico, que levassem em conta as possibilidades e as limitações do não-falante.

A transição de enunciados compostos por apenas uma palavra ou símbolo gráfico para enunciados com duas ou mais palavras, gestos ou símbolos gráficos é um marco no processo de aquisição de desenvolvimento de linguagem, de forma gradual. Tais enunciados capacitam o indivíduo a operar significados mais complexos e, assim, aumentar as possibilidades de expressão semântica e pragmática (von TETZCHNER, 2003).

Acerca da expansão de vocabulário, von Tetzchner e Martinsen (2000) salientaram a utilização de elementos "pivôs" pelos usuários de comunicação gráfica, como sendo elementos-chave, a partir dos quais, outros signos poderiam derivar-se. Estes elementos-chave ou "pivôs" enquadrar-se-iam na categoria semântica de ações que, segundo Tomasello (1992), teriam papel central na construção sintática e, por sua relação com as ações de eventos passados, teriam relação direta com as narrativas.

Muitos usuários de sistemas alternativos de comunicação parecem não fazer a transição para enunciados com múltiplos símbolos gráficos. Há algumas justificativas para a manutenção no nível de enunciados de um único símbolo, como: danos neurológicos cujas correlações estariam intrínsecas às habilidades cognitivas e lingüísticas (von TETZCHNER, 2003).

Geralmente, tais usuários costumam apresentar distúrbios motores que, associados aos demais, contribuem para que a estrutura das sentenças, usualmente curtas (von TETZCHNER; MARTINSEN, 1996), mantenham-se neste nível, considerando, ainda, os fatores relacionados a outros aspectos da comunicação, como a forma lingüística em si, os padrões de interação entre os parceiros naturais e os usuários de sistemas de comunicação alternativa, bem como as estratégias que permeiam tais relações interpessoais.

Apesar destes fatores, existem evidências de que os indivíduos com boa compreensão da linguagem oral não apresentam a expressão gráfica como recodificação da linguagem interna (SMITH, 1996). Somado a tais circunstâncias, quase nenhum suporte dos modelos lingüísticos tem sido direcionado no ambiente escolar, exceto nas atividades isoladas, geralmente no contexto terapêutico (UDWIN; YULE, 1990; von TETZCHNER; MARTINSEN, 1992; ROMSKI; SEVCIK, 1996).

A utilização de enunciados de um só símbolo, ou seja, de estrutura vertical é característica de narrativas de crianças com boa compreensão da linguagem oral que utilizam tecnologias de apoio para a comunicação em idade mais avançada (KRAAT, 1985; LIGHT, 1997; UDWIN; YULE, 1990). 
A estrutura narrativa pode conectar elementos semânticos diversos e, assim, promover a construção de sentenças "verticais e horizontais" (SCOLLON, 1976) frente à mediação do interlocutor, acerca do conteúdo abordado. Nesse sentido, as narrativas têm sido utilizadas como estratégias para a aquisição e o desenvolvimento das habilidades lingüísticas dos usuários de comunicação gráfica, visto que englobam diferentes constituintes semânticos, bem como a relação entre estes constituintes, caracterizando sentenças verticais e horizontais na estrutura sintática (NUNES et al., 2003).

As sentenças possibilitam a abrangência de afirmações mais precisas e fidedignas ao conteúdo das narrativas (NUNES et al., 2003), além de refletirem mais elementos do foco comunicativo compartilhado pelos interlocutores, nos diferentes ambientes comunicativos: escolar, familiar e terapêutico direcionado (von TETZCHNER et al., 1998).

O emprego adequado de narrativas que envolvam mais de um evento é uma habilidade importante que precisa ser favorecida a usuários de sistemas de comunicação gráfica, visto que a apresentação do conteúdo de um evento que incluísse pessoas, objetos, atributos, eventos e atividades, como ocorre nas narrativas, envolve a necessidade de dominar diferentes categorias semânticas e entrelaçá-las (NUNES et al., 2003).

Dessa forma, as narrativas tornam-se importante objeto de análise da estrutura e da ordenação sintática de seus constituintes, enquanto confeccionadas e construídas por meio de recursos e estratégias de comunicação suplementar.

\section{Oвjetivo}

Esta pesquisa visou analisar a extensão e a organização sintática dos enunciados de narrativas construídas por um aluno não-falante usuário de recurso suplementar de comunicação.

\section{Objetivos Específicos}

1. Caracterizar a natureza dos elementos constituintes dos enunciados de cada narrativa;

2. Caracterizar a extensão dos enunciados de cada narrativa;

3. Caracterizar a organização sintática dos elementos constituintes dos enunciados de cada narrativa.

\section{Método}

\subsection{Autorização do Comitê de Ética em Pesquisa}

O projeto desta pesquisa foi submetido à avaliação pelo Comitê de Ética em Pesquisa com seres humanos da Faculdade de Filosofia e Ciências da UNESP - Marília e foi aprovado sob o protocolo $n^{\circ}$. 1883/2003. Ressalta-se que 
todos os critérios éticos foram seguidos respeitando a Resolução 196/96, que versa sobre Ética em Pesquisa com seres humanos, do CONEP.

\subsection{Termo de Consentimento Livre e Esclarecido}

Os responsáveis legais pelo participante da pesquisa receberam todas as informações pertinentes ao projeto, como: objetivos da pesquisa, procedimentos, temporalidade, resguardo da privacidade, utilização dos dados para fins científicos, possibilidade de desistência da participação, sendo, pois, convidados a assinar o termo de consentimento livre e esclarecido, confirmando a anuência.

\subsection{SujeIto}

Foi selecionado um aluno de 14 anos, do sexo masculino, com diagnósticos de paralisia cerebral tetraparética espástica e de severo distúrbio da expressão oral; em decorrência, era usuário de recurso de comunicação alternativa há 8 anos, como complemento às expressões não-verbais usuais como o sorriso, o olhar, expressões faciais diversas, os movimentos de cabeça e alguns gestos indicativos e representativos; e também às expressões verbais, poucas, porém inteligíveis no contexto, como alguns sons vocálicos e nasais, designando sílabas e pequenas palavras.

\subsection{Local e Período}

As atividades de construção de histórias foram realizadas em uma das salas de atendimento fonoaudiológico do Setor de Comunicação Alternativa do C.E.E.S. - Unidade Auxiliar da UNESP - Marília/SP, durante o período de agosto a dezembro de 2003.

\subsection{MATERIAIS DE PESQUISA}

\subsubsection{SoftWARe BoARDMAKER E SÍmbolos gráficos do PictuRe CoMmunication Symbols}

Foi utilizado o software Boardmaker (MAYER-JOHNSON, 2004) para a confecção dos símbolos gráficos do Picture Communication Symbols (P.C.S.), compatíveis com o conteúdo e a estrutura de cada história.

\subsubsection{HistóRIAS}

Para o intuito deste estudo, foram selecionadas três, de cinco histórias construídas pelo aluno, de acordo com seus centros de interesse, idade, grau de escolaridade e as temáticas trabalhadas na escola do aluno, bem como o tamanho e a estrutura de cada história. 


\subsection{3 Овјетоs}

Foram selecionados objetos, como brinquedos e miniaturas, representativos das personagens e dos locais em que as tramas ocorriam, a fim de viabilizar a experiência e a dramatização dos conteúdos pertinentes às histórias escolhidas.

\subsection{INSTRUMENTOS DE PESQUISA}

\subsubsection{FilMAGEM}

A opção de utilizar a filmagem ocorreu em razão das possibilidades de assistir o fenômeno observado várias vezes. Fagundes (1983) ressaltou que o uso da filmagem, como recurso de registro, vem sendo cada vez mais utilizado, já que proporciona a descrição de momentos ou situações. Kreppner (2001) destacou o fato de possibilitar a observação repetida do fenômeno, o que faz da tecnologia de vídeo um importante recurso para melhorar o consenso intra e entre os observadores, além disso, permite a reconstrução ativa do material gravado.

Para a filmagem dos procedimentos de coleta, foram utilizadas filmadora VHS da marca Sony ${ }^{\circledR}$ e fitas de mesma marca. Para as transcrições, foram utilizadas fitas VHS da marca TDK®. O foco de filmagem enquadrava o participante da pesquisa e a terapeuta, estando ambos os enquadrados sentados, sendo o aluno na mesa e cadeira adaptadas e a terapeuta numa cadeira em um de seus lados, no lado oposto havia outro interlocutor, em posse de um diário para registro.

\subsubsection{CADERNO DE REgISTRO CONTÍNUO}

Fagundes (1993) definiu o registro contínuo como uma técnica de descrição cursiva realizada no momento da observação, em um período de tempo ininterrupto em que é registrado detalhadamente o que ocorre numa determinada situação, de acordo com a seqüência temporal dos fatos, de forma que se possam visualizar os eventos observados como de fato ocorreram.

As informações anotadas no caderno de registro descreveram principalmente os símbolos gráficos selecionados e organizados pelo aluno durante a construção das histórias, como complemento às filmagens e, assim, tais informações foram anexadas às transcrições destas.

\subsection{Procedimentos da coleta de dados}

Os procedimentos vinculados à construção de cada história foram:

1. Foram selecionados os livros de histórias de acordo com o interesse, a idade e o grau de escolaridade do aluno.

2. O aluno escolhia um dentre três livros apresentados, na sessão anterior à coleta. 
3. A terapeuta selecionava e confeccionava os símbolos gráficos do Picture Communication Symbols - "P.C.S." (MAYER-JOHNSON, 2004), compatíveis com o conteúdo e a estrutura da história escolhida, em folha de papel branca, sendo plastificados, a fim de que pudessem ser anexados com velcro em placas de eucatéx, conforme proposto por Pelosi (2003).

4. A terapeuta contava a história com apoio das figuras do livro e o direcionamento para a estrutura escrita deste. A intervenção dava-se por meio da utilização de perguntas ou "operadores de narrativas", consoante Perroni (1992), para conectar eventos. Foram utilizados, também elementos prosódicos e suprasegmentares da linguagem, como a variação entonacional, do ritmo, da velocidade de fala e da qualidade de voz.

5. Após a leitura de cada livro, foram apresentados ao aluno os símbolos gráficos previamente confeccionados, solicitando que este selecionasse e direcionasse quais, de seu interesse seriam relevantes para a construção e recontagem da história.

6. Após a seleção e direcionamento das figuras a serem utilizadas, o aluno organizava as seqüências de figuras, delineando a construção da história, mediante a intervenção da terapeuta, nos momentos de dificuldade e abstração do aluno, de forma a apontar novamente a seqüência que estava sendo construída, ou mesmo relembrar os fatos da história, verbalmente ou com alguns símbolos gráficos.

7. Após a construção da história pelo aluno, com a possível mediação dos interlocutores, era solicitado que o aluno recontasse a história construída. Neste momento, o aluno poderia complementar sua construção com os recursos comunicativos comumente utilizados, como as expressões não-verbais, faciais e corporais.

\subsection{Procedimentos de ANÁlise}

Uma vez filmadas, todas as interações para a construção e recontagem das histórias foram transcritas, na forma literal, sem a preocupação de transcrição fonética por não cursar com o intuito da pesquisa, mas sim, para análise de conteúdo, consoante Bardin (1977). As informações registradas no diário de registro contínuo complementaram as informações filmadas, caracterizando, assim, as transcrições das fitas.

Para melhor visualização das formas de registro, foram utilizadas duas estratégias para transcrever as informações coletadas: modo normal para as informações coletadas na filmadora e modo negrito para as informações extraídas do diário de registro. Ressalta-se que na terceira narrativa construída não foi utilizado diário de registro. 
Todas as informações coletadas foram analisadas e discutidas, a fim de que fossem selecionadas as unidades de análise significativas para o objeto deste estudo.

\section{Resultados E discussão}

Após a leitura das transcrições das filmagens, bem como a discussão vinculada aos objetivos deste estudo, foram delineados três estágios de análise dos enunciados das narrativas construídas. Tratou-se de uma análise qualitativa dos conteúdos retirados das transcrições, para que, a cada estágio, fossem apresentadas unidades significativas.

Os estágios em que a análise foi direcionada determinaram a delimitação das seguintes categorias:

1. Caracterização ou natureza dos elementos constituintes dos enunciados das narrativas: a) objeto; b) símbolo gráfico; c) escrita; d) vocalização e; e) gesto representativo, com significado lingüístico.

2. Extensão dos enunciados, ou seja, número de elementos, de qualquer natureza, compreendidos nos enunciados das narrativas: a) 1 elemento; b) 2 elementos; c) 3 elementos; d) 4 elementos; e) 5 elementos; f) 6 elementos e; g) 7 ou mais elementos.

3. Organização sintática dos elementos constituintes das narrativas: S - sujeito; V verbo; $\mathrm{O}$ - objeto; isolados ou associados.

Estes três estágios, nesta ordem de análise, ressaltaram a relevância deste estudo, visto que, uma vez caracterizada a natureza dos elementos constituintes dos enunciados das narrativas, pôde-se quantificá-los de modo a determinar a extensão destes enunciados. A partir da extensão de cada enunciado, certificou-se a análise sintática envolvendo sentenças verticais e horizontais, e, especificamente no âmbito gramatical, quanto à sintaxe, garantiu-se a análise da organização de tais sentenças, queira isoladamente, no caso das verticais, queira de forma associada, no caso das horizontais.

As três histórias foram analisadas e, de certa forma, comparadas, qualitativamente, em relação a cada estágio abordado, a fim de que afirmações e discussões pudessem ser denotadas e comprovadas, em cada instância. Para clarificar as etapas de análise e exposição dos resultados, foram separados e ressaltados alguns exemplos das histórias analisadas, diante de cada estágio abordado. 


\subsection{CARACTERIZAÇÃO OU NATUREZA DOS ELEMENTOS CONSTITUINTES DOS ENUNCIADOS DAS NARRATIVAS}

A análise do conteúdo das três histórias permitiu a abordagem de 5 tipos ou naturezas de elementos constituintes dos enunciados das narrativas, sendo eles: a) objeto; b) símbolo gráfico; c) escrita; d) vocalização e; e) gesto representativo.

Tais tipos naturalísticos foram determinados com base no conteúdo expresso, podendo ter sido abordados todos em uma mesma história, ainda, um ou outro tipo, assim, estes tipos foram abordados de acordo com cada história analisada, por meio de exemplos extraídos das transcrições realizadas.

\subsection{1 Овјето}

O elemento objeto esteve presente nos enunciados de duas das três histórias analisadas, sendo a terceira e a quarta narrativa. Assim, não pôde ser abordado exemplo desta natureza na segunda narrativa.

\section{Exemplo 1 (Narrativa 3)}

I.1: Onde é que os dinossauros moravam?

A: Aponta a caverna de brinquedo sobre a mesa.

I.1: Parece né, eles moravam numa caverna igual essa daí.

\subsubsection{Símbolo GRÁFICo}

Uma vez que o aluno era usuário de recurso suplementar de comunicação, especificamente, dos símbolos gráficos do Picture Communication Symbols - P.C.S. (JOHNSON, 1994; MAYER-JOHNSON, 2004) contidos em seu tabuleiro, além de as figuras confeccionadas e utilizadas na relação direta com o conteúdo das histórias construídas também pertencerem a este mesmo sistema alternativo de comunicação, garantiu-se que tal tipo de elemento estivesse presente na maioria dos enunciados das três narrativas estudadas.

\section{Exemplo 2 (Narrativa 2)}

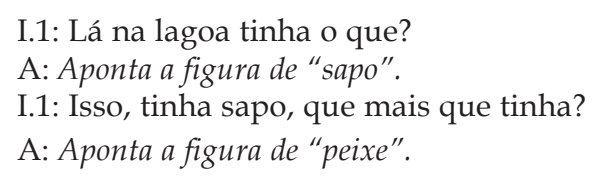

\subsubsection{ESCRITA}

O elemento naturalístico escrita esteve presente nos enunciados de duas das três histórias analisadas, sendo a terceira e quarta narrativas.

\section{Exemplo 3 (Narrativa 3)}

I.1: O que que aconteceu com o vulcão?

A: Pega a figura de "certa" (escrita).

I.1: Isso mesmo, certa! Era de dia, de tarde, de noite, de manhã? 
Sabe-se que a escrita seria o alvo, enquanto etapa final, da utilização de recursos de comunicação alternativa (CHUN; MOREIRA, 1997). Assim, a utilização deste elemento, como representante verbal dos símbolos gráficos ou a única maneira de expressar um significado incompatível com uma representação pictográfica, garantiu que o aluno assimilasse a relevância de sua utilização, principalmente nos enunciados extensos, enquanto elementos conectivos, que eram usualmente mediados e interpretados pela terapeuta, nas primeiras elocuções de narrativas.

\subsubsection{Vocalização}

Visto que o contexto terapêutico baseado em recursos e estratégias de comunicação suplementar valorizava os aspectos verbais inerentes aos símbolos gráficos abordados, esperava-se que, no decorrer das construções das narrativas, o aluno lançasse mão não somente dos recursos comunicativos usualmente utilizados, como também das novas aquisições de expressões fono-articulatórias, que puderam ser ricamente empregadas e ampliadas em todas as narrativas construídas.

Exemplo 4 (Narrativa 2)

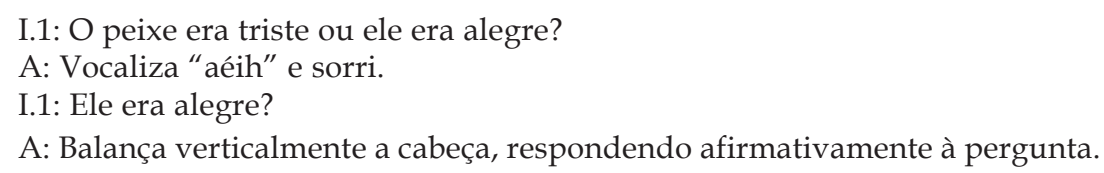

Tais exemplos de vocalizações foram apresentados em situações isoladas, ou seja, enquanto único elemento com significado no enunciado digno de construções verticais. Entretanto, os dados mostraram, também, que as vocalizações foram utilizadas na associação com outras naturezas de elemento, constituindo enunciados simples, de 2 a 3 elementos, e complexos, com 4 a 7 elementos.

Especificamente acerca do exemplo de vocalização apresentado, tal emissão oral denotou categoria morfológica referente a adjetivo, no caso de alegre ("aéih").

Fernandes (2001) salientou a existência de diversos trabalhos, na literatura especializada, que mostraram que o uso da Comunicação Alternativa e/ ou Suplementar não inibe o desenvolvimento da fala, apontando que as estratégias e trabalhos específicos de articulação permeiam a conduta fonoaudiológica. De acordo com Alm \& Parnes (1995), um bom sistema de comunicação, indicado e utilizado corretamente, deve incentivar o uso da fala pelo indivíduo, sempre que possível. Assim, a comunicação alternativa não visa substituir a linguagem oral, "ela é, com efeito, instrumento para a atingir" (NUNES, 2003, p. 5). 


\subsubsection{GESTO REPRESENTATIVO}

O contexto terapêutico baseado em recursos e estratégias de comunicação suplementar valorizava, além dos aspectos verbais, os recursos paralingüísticos não verbais, como os gestos representativos, aqui referenciados. Nesse sentido, esperava-se que, no decorrer das construções das narrativas, o aluno utilizasse tais gestos como mais um tipo ou natureza de elementos nos enunciados de suas narrativas.

A seguir, as descrições do comportamento para-lingüístico do aluno, delatadas em todas as construções do aluno, clarificaram a relevância da utilização deste tipo de elemento nos enunciados.

\section{Exemplo 5 (Narrativa 3)}

I.1: O que aconteceu com o vulcão naquele dia?

A: Vocaliza "ruhm" junto com gesto representativo de explodir (movimento com as mãos entreabertas lançadas acima e para frente de seu corpo).

I.1: O vulcão explodiu!

Em relação ao significado lingüístico denotado pelos gestos representativos, naquele contexto de interação, verificou-se que corresponderam a apresentação de elementos do discurso narrativo referentes aos conteúdos de ações principais e de personagens, inerentes às categorias morfológicas de verbo e de substantivo.

Os exemplos aqui apresentados esboçaram a utilização de gestos representativos de maneira isolada ou associada à outra natureza de elemento em um mesmo enunciado. Percebeu-se que a maioria das utilizações foi abordada no contexto sintático vertical, no entanto, houve apenas um momento em que a associação do gesto representativo de explodir com a vocalização "ruhm" denotou um enunciado horizontal, referente à ordenação sintática de Sujeito - Verbo ("o vulcão explodiu").

\subsection{EXTENSÃO DOS ENUNCIADOS DAS NARRATIVAS}

Pela análise do número de elementos de cada enunciado das narrativas, bem como do significado associado ao(s) elemento(s) naturalístico(s) utilizado(s), foi possível vislumbrar, também, a estruturação em sentenças verticais, ou seja, contendo apenas um tipo naturalístico com sentido frasal, ou em sentenças horizontais, ou seja, que continham 2 ou mais elementos, em um mesmo enunciado.

Especificamente, em relação às sentenças horizontais, a quantificação do número de elementos dos enunciados viabilizou a possibilidade de relacionamento entre estes constituintes, de forma a conectar elementos semânticos diversos e constituir uma sintaxe coesa.

von Tetzchner (2003) dispôs o estudo quanto à extensão dos enunciados, de acordo com o número de elementos, pela seguinte ordenação: 1 elemento; 2 a 3 
elementos; 4 a 5 elementos, 6 ou mais elementos. Entretanto, foi realizada uma adaptação à proposta do autor, de modo a abordar linearmente o número de elementos, na seqüência de 1 a 6 elementos, um a um, tendo sido acrescido o item 7 ou mais elementos.

\subsubsection{NÚMERO DE ELEMENTOS NO ENUNCIADO: 1}

Em relação à utilização de apenas um elemento no enunciado, percebeuse que se tratou de sentenças estritamente verticais, ou seja, em que, com apenas uma única natureza de elemento, o aluno pôde expressar um significado lingüístico correspondente a uma frase. Abaixo, seguem exemplos ilustrativos.

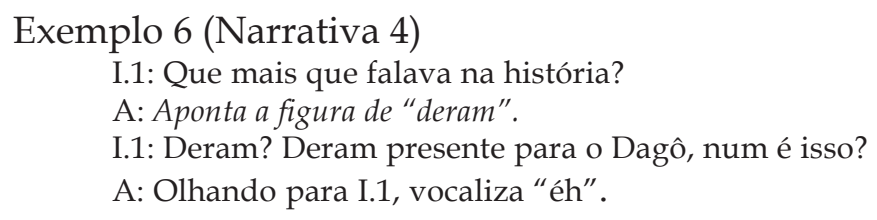

As instâncias em que as sentenças verticais foram abordadas surtia efeito em tornar horizontal uma sentença previamente vertical, ou ainda, expandir o número de elementos das sentenças horizontais e, dessa forma, ampliar a relação entre seus constituintes. Conforme salientado por von Tetzchner e Martinsen (2000), já que durante a ampliação dos enunciados, os usuários de comunnicação gráfica tendem a utilizar elementos "pivôs", como sendo elementos-chave, a partir dos quais outros signos poderiam derivar-se.

\subsubsection{NÚMERO DE ELEMENTOS NO ENUNCIADO: 2}

\section{Exemplo 7 (Narrativa 2)}

I.1: Todo dia, o peixe fazia o que?

A: Aponta as figuras em seqüência: "olhar" e "sapo".

I.1: O peixe, vamos colocar a figura do peixe, heim, olhava o sapo. Cadê a figura do peixe?

As ocasiões em que dois elementos foram utilizados denunciaram a construção autônoma das sentenças pelo aluno, ou este iniciava a construção de uma sentença elaborada, parava e olhava para a interlocutora, como se pedisse auxílio para ir adiante. Em decorrência, os enunciados de 2 elementos foram amplamente utilizados nas três narrativas construídas, o que, de fato, ressaltou a intenção comunicativo-discursiva e a capacidade lingüística do aluno em construir sentenças, elaborando sua história.

De maneira geral, a utilização de dois elementos em um enunciado denunciou a construção autônoma de sentenças pelo aluno, ou o início de uma sentença mais complexa, em cujo momento o aluno solicitava auxílio para ir adiante. Entretanto, tal tipo de enunciado foi amplamente utilizado nas três narrativas construídas. 


\subsubsection{NÚMERO DE ELEMENTOS NO ENUNCIADO: 3}

\section{Exemplo 8 (Narrativa 4)}

I.1: Como começa a história, G.?

A: Aponta as figuras, em seqüência: "Dagô" (escrita), "é" (escrita) e "vampiro".

I.1: Dagoberto, o Dagô, é um vampiro. Precisa colocar o um antes de vampiro!

A utilização de 3 elementos foi a extensão-padrão das narrativas construídas autonomamente pelo aluno, a partir da terceira história; enquanto arquétipo de sentença, englobou as noções semânticas de agente, ação e paciente, constituindo uma sintaxe simples.

Embora esta estrutura de enunciado tenha sido amplamente utilizada, a mediação e a situação de ensino e aprendizagem intrínseca ao contexto terapêutico favoreceram que este padrão fosse superado e evoluísse para a elocução de 4 ou mais elementos em uma mesma sentença, daí a relevância para o suporte de modelos lingüísticos direcionados, como afirmaram Romski e Sevcik (1996).

\subsubsection{NÚMERO DE ELEMENTOS NO ENUNCIADO: 4}

\section{Exemplo 9 (Narrativa 2)}

I.1:E o que que o peixe fazia todo dia?

A: Aponta as figuras, linearmente: "peixe", "ver", "brinquedos" e "água".

I.1: O peixe via brinquedos na água? Era na água que estavam os brinquedos?

A: Vocaliza "ãhuhm" e ri, olhando para I.1.

I.1: Então vamo arrumá essa frase, onde que ele via os brinquedos?

A: Toca e arrasta a figura de "campo" para perto da figura de "água".

O exemplo denotado ressalta a ampliação das sentenças construídas pelo aluno, desencadeando enunciados complexos, mais elaborados e, cada vez mais, coesos e com elementos coerentes ao significado lingüístico subjacente. Este padrão, embora tenha se apresentado na segunda narrativa, foi amplamente utilizado na quarta narrativa, principalmente quando a mediadora interferia na construção, norteando que o aluno prestasse mais atenção na frase, pois se tratava de algo extenso e que precisava de todas as figuras para que a interlocutora entendesse a construção do aluno.

\subsubsection{NÚMERO DE ELEMENTOS NO ENUNCIADO: 5}

\section{Exemplo 10 (Narrativa 3)}

I.1: Pra onde os dinossauros fugiram?

A: Arrasta as figuras de "flor" e "árvore" para o fim da sentença "os" (escrita), "dinossauros" e "fugiram".

I.1: Os dinossauros fugiram pra onde tinha flor, árvore. Eles fugiram pra um vale.

Construir sentenças com 5 elementos, de diferentes naturezas, tornouse uma conquista lingüística para o aluno, pois, a partir deste tipo de experiência frasal complexa, comum nas histórias trabalhadas, o aluno passou a estender este 
padrão de estruturação para outros contextos abordados, até mesmo, na atividade dialógica com o apoio suplementar de sua pasta de comunicação.

\subsubsection{NÚMERO DE ELEMENTOS NO ENUNCIADO: 6}

Conforme já ressaltado nos itens anteriores, embora não tenha sido realizada uma análise processual e evolutiva da estruturação e ordenação dos enunciados das narrativas construídas, percebeu-se, pela análise do conteúdo das transcrições, que as duas últimas histórias abordaram sobremaneira, enunciados contendo 4 ou mais elementos. Assim, neste item, será exemplificado um trecho da quarta narrativa construída, visto que, tanto na segunda, quanto na terceira história, o aluno não expressou 6 ou mais elementos na construção de seus enunciados.

\section{Exemplo 11 (Narrativa 4)}

I.1: Então, o que o Dagoberto fazia toda noite?

A: Aponta as figuras na seqüência: "toda", "noite", "Dagô" (escrita), "assustava", "as" (escrita) e "pessoas".

I.1: Ele assustava as pessoas toda noite mesmo!

Como o exemplo exposto delata, mais uma vez, a ampliação do número de elementos dos enunciados desta história, ressalta-se, ademais, uma ampliação morfológica, já que os novos elementos se enquadraram na categoria gramatical inerente aos elementos conectivos, como os pronomes, os artigos definidos e indefinidos, os numerais, e as preposições. Tal ampliação morfológica enquadrarse-ia no postulado, afirmado por von Tetzchner (2003), de que um pré-requisito para formular sentenças seria a aquisição suficiente e adequada de vocabulário.

De maneira geral, não se tratou de uma ampliação substancial de caráter semântico que modificaria o significado do enunciado, já que o mesmo conteúdo, agente, ação e paciente, poderia ter sido expresso em 3 ou 4 elementos, conforme apontado na exposição dos exemplos da segunda e terceira histórias.

\subsubsection{NÚMERO DE ELEMENTOS NO ENUNCIADO: 7 OU MAIS ELEMENTOS}

Houve apenas um episódio em que o aluno utilizou mais de 7 elementos em uma mesma sentença; neste exemplo único, foram utilizados 9 elementos no total, sendo este o limite de extensão de enunciado alcançado pelo aluno, justificado pelo caráter processual de ensino-aprendizagem dos procedimentos realizados no contexto terapêutico.

Exemplo 12 (Narrativa 4)

I.1: Então o que que as pessoas falavam pro Dagoberto? Pra explicar porque que ele num tinha amigos!

A: Aponta as figuras em seqüência: "todas", "as" (escrita), "pessoas", "falavam", "pare", "de" (escrita), "assustar", "as" (escrita) e "pessoas".

I.1: Eles diziam isso pro Dagô, porque senão, ele ia ficar sem amigos, de tanto assustar as pessoas. 
Este exemplo ilustrou a tendência a expressão de vocabulário menos extensa pelos usuários de comunicação alternativa, de acordo com a afirmação feita por von Tetzchner (2003) de que crianças verbais expressam de quinze a vinte palavras quando aprendem a formular sentenças, ao contrário das não-verbais, que, assim, deveriam ser estimuladas, por meio da mediação no processo de ensinoaprendizagem, a formular sentenças em estágio similar.

\subsection{ORgANIZAÇÃo SINTÁtICA dOS ELEMENTOS CONSTITUINTES DAS NARRATIVAS}

A análise da organização sintática dos elementos constituintes das narrativas foi o resultado da associação das duas análises anteriores, envolvendo a utilização isolada, no caso de sentenças verticais, cujo enunciado englobaria um elemento, de qualquer natureza, denotando significado; ou, a associação de diferentes elementos em um mesmo enunciado, no caso das sentenças horizontais, ampliando o caráter sintático deste enunciado, mas não necessariamente o valor semântico.

Além desta associação, foi acrescentada a proposta de disposição de organização sintática de Nunes et al. (2003) nas categorias de S - sujeito, V - verbo e O - objeto, delineadas, tanto isoladamente, quanto associadas, determinando as seguintes formas: sujeito associado a verbo (Sujeito - Verbo), sujeito associado a objeto (Sujeito - Objeto), verbo associado a objeto (Verbo - Objeto) e a relação linear de sujeito associado a verbo e associado a objeto (Sujeito - Verbo - Objeto).

\subsubsection{Utilização isolada dos CARACTERES De $\mathbf{S}$ - SUJeito, $\mathrm{V}$ - Verbo E $\mathrm{O}$ - ObJeto NAS SENTENÇAS VERTICAIS}

Para melhor visualização e análise dos achados, os caracteres foram dispostos pela seguinte organização: a) Sujeito isolado; b) Verbo isolado e; c) Objeto isolado.

a) Sujeito isolado

\section{Exemplo 13 (Narrativa 3)}

I.1: Você lembra como começava?

A: Aponta a figura de "família".

I.1: Uma família de, de que?

b) Verbo isolado

\section{Exemplo 14 (Narrativa 2)}

I.1: Todo dia, o peixe fazia o que?

A: Aponta a figura de "chorar" sobre a mesa e ri.

I.1: Isso, muito bem! O peixe chorava. 
c) Objeto isolado

\section{Exemplo 15 (Narrativa 4)}

I.2: O que o pessoal falava pro Dagoberto?

A: Aponta a figura de "sozinho" em uma das sentenças do livro adaptado construído. I.2: Eles falavam pare de assustar as pessoas, senão você vai acabar ficando sozinho.

Acredita-se que a utilização de um signo no enunciado, independente do caráter sintático esboçado, vinculou ao papel do interlocutor, enquanto mediador da estruturação discursiva das narrativas, devido à abordagem de precursores metalingüísticos, cuja resposta era imediatamente apontada pelo aluno, sem elaboração lingüística pormenorizada. Dessa forma, sem a associação prévia ou contínua de outros elementos, qualquer resposta diante de uma pergunta direta remetir-se-ia a um único elemento e, consequentemente, enquadrar-se-ia na classificação de uma sentença vertical.

Independente da explicação para o fato de o aluno abordar apenas um elemento no enunciado para denominar uma sentença com significado, alguns autores, como Kraat (1985), Light (1997), Udwin e Yule (1990) e von Tetzchner e Martinsen (1996), reiteram o fato de que a utilização de enunciados de um só signo, ou seja, de estrutura vertical, é característica de narrativas de usuários de comunicação gráfica em idade mais avançada, mesmo com boa compreensão da linguagem oral.

Em contrapartida, houve momentos em que o aluno não respondeu, diretamente, à interferência da terapeuta, mas retomou o que havia sido abordado, queira por assimilação do conteúdo, queira para complementá-lo. Ainda, houve momentos em que a interferência da terapeuta foi ignorada, tendo sido expressada a intenção comunicativa e discursiva do aluno, tanto para apontar um elemento discursivo constituinte da narrativa, quanto para apontar um símbolo gráfico intrínseco à mesma categoria semântica e morfológica do tópico delineado naquela ocasião.

\subsubsection{UTILIZAÇÃo ASSOCIADA DOS CARACTERES DE $\mathrm{S}$ - SUJEITO E $\mathrm{V}$ - VERBO NAS SENTENÇAS HORIZONTAIS}

Exemplo 16 (Narrativa 3)

I.1: Eles não podiam ficar perto do vulcão que explodiu.

A: Balança a cabeça para as laterais, com sentido negativo.

I.1: Que que eles fizeram? Pra onde eles foram?

A: Aponta a figura de "fugiram" sobre o sulfite e aproxima desta, a figura de "todos".

I.1: Quem fugiu, que que aconteceu?

A: Arrasta a figura de dinossauro para perto das demais.

I.1: Todos os dinossauros fugiram. Isso ai!

Consoante exemplos anteriores, em que a terapeuta norteava elementos precursores do discurso narrativo que auxiliariam a construção das narrativas, 
houve a participação ativa do aluno que, imediatamente após a pergunta da interlocutora, emitiu uma resposta direta, condizente à manutenção da categoria semântica norteada.

Este exemplo denotou, ainda, a inversão sintática de Sujeito - Verbo para Verbo - Sujeito, fato este que caracterizaria um desvio da ordenação sintática. Tal elaboração condisse com o estudo de van Balkom e Donker - Gimbrère (1996), em cujos resultados ocorreram desvios simples da ordenação normativa, ou seja, trocas ocorridas nos elementos constituintes dos enunciados que, na instância semântica, não mudariam o significado da frase.

\subsubsection{UtilizAÇÃo ASSOCiAda dos CARACTERES DE $\mathbf{S}$ - SUJEITO E $\mathbf{O}$ - ObJETO NAS SENTENÇAS HORIZONTAIS}

Exemplo 17 (Narrativa 3)

I.1: Os dinossauros, onde eles moravam?

A: Aponta as figuras em seqüência: "família", "dinossauros" e "montanhas".

I.1: Todos os dinossauros, a família de dinossauros morava nas montanhas.

Nesta ocasião, houve, mais uma vez, a elaboração de um enunciado simples decorrente da relação metalingüística da intervenção discursiva, o aluno respondeu à pergunta precursora da terapeuta, de forma a determinar o objeto da frase, ou seja, o predicativo referente ao predicado previamente explícito, da mesma forma que ampliou a semântica do sujeito ou agente do enunciado, ao substituir o pronome "eles" por dois substantivos comuns ("família" e "dinossauros").

\subsubsection{UTILIZAÇÃO ASSOCIADA DOS CARACTERES DE V - VERBO E O - OBJETO NAS SENTENÇAS HORIZONTAIS}

Exemplo 18 (Narrativa 4)

I.1: E o que o Dagô aprendeu com tudo isso?

A: Sequencia as figuras: "não", "assustar" e "ninguém".

I.1: O Dagoberto decidiu que num ia assustar mais ninguém, pra ele num ficar sem amigos, num é?

A: Balança a cabeça para cima e para baixo, com sentido afirmativo.

A análise da estrutura sintática geral do enunciado do exemplo mencionado apontou a manutenção da estratégia discursiva da terapeuta e acomodação por parte do aluno. Uma vez que o precursor se referia à ação principal da personagem naquele contexto, o aluno estruturou uma sentença referente ao predicado e ao predicativo da oração, ou, quanto ao caráter semântico da oração, denotou a ação e o paciente.

Assim como nos exemplos anteriores, a intervenção dialógicodiscursiva do interlocutor demonstrou a permanência ou o aprimoramento de estruturas sintático-semânticas específicas. Infere-se que, naquelas ocasiões, o aluno não repetiu a informação do agente, já mencionada no discurso da interlocutora, talvez, por considerar tal fato irrelevante diante da ação. 


\title{
4.3.5 Utilização associada dos caracteres de $\mathbf{S}$ - Sujeito, $\mathrm{V}$ - Verbo E $\mathrm{O}$ - ObJeto NAS SENTENÇAS HORIZONTAIS
}

\author{
Exemplo 19 (Narrativa 2) \\ I.1: Aonde o peixe morava? \\ A: Aponta as figuras de "peixe", "morar" e "água", nesta seqüência. \\ I.1: O peixe morava na água, no lago.
}

Nesta ocasião, percebeu-se o momento em que houve consonância da relação semântica agente, ação e paciente com a relação sintática sujeito, verbo e objeto, diretamente, bem como apontou o estudo de Nunes et al. (2003), cujas autoras ressaltaram que a apresentação do conteúdo de um evento que envolva pessoas, objetos, atributos e atividades, como a narrativa, envolveria a necessidade de dominar diferentes categorias semânticas e entrelaçá-las.

A relação direta entre as relações semânticas e sintáticas conclui o aprimoramento das habilidades lingüísticas e mesmo cognitivas do aluno, caso se compare, qualitativamente, as primeiras elaborações com estes exemplos. Assim, as sentenças mais elaboradas possibilitaram a abrangência de afirmações mais precisas e fidedignas ao conteúdo das narrativas, consoante os achados de Nunes et al. (2003).

Não somente a relação sintática simples concretizou-se nos enunciados, como também, momentos de estruturações complexas foram oportunizados e ricamente explorados na relação metalingüística entre o aluno e a interlocutora, como ressalta o último exemplo, em que, em um mesmo enunciado foram explícitos nove elementos, de duas naturezas diferentes, em uma mesma sentença, sendo este, o limite atingido pelo aluno.

\section{CONCLusÕes}

A análise dos resultados e a discussão dos achados permitiram apontar as seguintes conclusões, intrínsecas ao objeto deste estudo:

1. A construção das narrativas pelo aluno, na mediação metalingüística da interlocutora, favoreceu o desenvolvimento e a ampliação lingüística dos enunciados do aluno quanto aos tipos de elementos abordados, ao número de elementos constituintes e à ordenação e à complexidade da estrutura sintática.

2. Quanto à natureza dos elementos constituintes dos enunciados das narrativas construídas, foram utilizados objetos, enquanto instrumentos materiais para dramatização e ilustração das histórias, além de símbolos gráficos do "P.C.S."; a escrita propriamente dita das palavras não passíveis de representação icônica pelo recurso de comunicação alternativa abordado; vocalizações semelhantes aos padrões fono-articulatórios da comunidade lingüística e; gestos representativos, que, nos contextos abordados, tinham significado restrito e inerente à temática da narrativa. 
3. Quanto à extensão dos enunciados das narrativas, foram utilizados desde uma seis elementos seqüenciados em um mesmo enunciado, de modo que, entrelaçados, designassem um significado coerente ao conteúdo a que se referia, houve um momento considerado "limite" na extensão dos enunciados construídos, em que o aluno abordou nove elementos em uma mesma sentença horizontal.

4. Quanto à ordenação e complexidade da estrutura sintática dos enunciados das narrativas construídas, houve a exploração semântica dos valores de agente, ação e paciente, tanto indiretamente, estando uns ou outros implícitos no contexto referido pelo aluno, quanto diretamente, na relação linear com a ordenação sintática de sujeito, verbo e objeto, ou ainda, sujeito, predicado e predicativo. Os achados vincularam-se a ordenações sintáticas simples de sujeito, verbo e objeto utilizados isoladamente em elocuções verticais e ordenações mais complexas, utilizadas em sentenças horizontais, tendo havido variação da relação entre seus caracteres sintáticos, nas ordenações de Sujeito - Verbo; Sujeito - Objeto; Verbo - Objeto e, segundo a norma gramatical brasileira, Sujeito - Verbo - Objeto.

5. Achados complementares remeteram à caracterização da ampliação da complexidade dos enunciados por meio da utilização de elementos conectivos, que segundo a morfologia da gramática normativa, enquadrar-se-iam nas categorias de pronomes, numerais, artigos e preposições.

\section{REFERÊNCIAS}

ALM, N.; PARNES, P. Augmentative and alternative communication: past, present and future. Folia Phoniatr. Logop., n. 47, p. 165-92, 1995.

BARDIN, L. Análise de conteúdo. Tradução de L. A. Reto e A. Pinheiro. São Paulo: Martins Fontes, 1977.

CHUN, R. Y.S.; MOREIRA, E. C. Comunicação suplementar e/ou alternativa - ampliando possibilidades de indivíduos sem fala funcional. In: LACERDA, C. B. F.; PANHOCA, I. Tempo de fonoaudiologia. $1^{a}$ ed. Taubaté: Cabral Editora Universitária Ltda., 1997.

FAGUNDES, A. J. F. M. Descrição, definição e registro de comportamento. São Paulo: Edicon, 1993.

FERNANDES, A. S. A comunicação alternativa na educação especial. Temas sobre Desenvolvimento, v. 10, n. 58-9, p. 85-88, 2001.

JOHNSON, R. Boardmaker: The P.C.S. libraries on disk. Solana Beach, CA, Mayer Johnson, 1994.

KRAAT, A.W. Communication interaction between aided and natural speakers: a state of the art report. Toronto: Canadian Rehabilitation Council for the Disable, 1985.

KREPPNER, K. Sobre a maneira de produzir dados no estudo da interação social. Psicologia: Teoria e Pesquisa. V. 17, n 2, p.97-107. mai-ago, 2001. 
LIGHT, J. Communication is the essence of human life: Reflections on communicative competence. Augmentative and alternative communication: The Journal of the International Society for Augmentative and Alternative Communication, v. 13, n. 2, June, 1997.

MAYER-JOHNSON, R. The picture communication symbols - P.C.S. - Software Boardmaker. Porto Alegre: Clik Tecnologia Assistiva, 2004.

NUNES, L. R. O. P. Linguagem e comunicação alternativa: uma introdução. In: NUNES, L.R.O.P. (Org.) Favorecendo o desenvolvimento da comunicação em crianças e jovens com necessidades educacionais especiais. Rio de Janeiro: Dunya, 2003.

NUNES, L. R. O. P.; TUBAGI, S. N.; CAMELO, R. C. R.; MAGALHÃES, A. P. C.; ALMEIDA, F. P.; PAULA, K. M. P. Narrativas sobre fotos e vídeos e narrativas livres através de sistema gráfico de comunicação alternativa. In: NUNES, L.R.O.P. (Org.) Favorecendo o desenvolvimento da comunicação em crianças e jovens com necessidades educacionais especiais. Rio de Janeiro: Dunya, 2003.

PELOSI, M. B. A. Comunicação alternativa escrita. In: NUNES, L.R.O.P. (Org.) Favorecendo o desenvolvimento da comunicação em crianças e jovens com necessidades educacionais especiais. Rio de Janeiro: Dunya, 2003.

PERRONI, M. C. O desenvolvimento do discurso narrativo. São Paulo: Martins Fontes, 1992.

ROMSKI, M.; SEVCIK, R. Breaking the speech barrier: language development through augmentative mean. Baltimore: Paul Brookes, 1996.

SCOLLON, R. Conversations with one year old. Honolulu: University of Hawaii Press, 1976.

SMITH, M. M. The medium or the message: a study of speaking children using communication boards. In: von TETZCHNER, S.; JENSEN, M. H. (Eds.) Augmentative and alternative communication: European perspectives. London: Whurr/ San Diego: Singular, 1996.

TOMASELLO, M. First verbs: a case study of early grammatical development. Cambridge: Cambridge University Press, 1992.

UDWIN, O.; YULE, W. Augmentative communication systems taught to cerebral palsied children: a longitudinal study. "The acquisition of the signs and symbols, and syntatic aspects of their use over time". In: British Journal of Communication Disorders, v. 25, p. 295309, 1990.

VAN BALKOM, H.; DONKER-GIMBRÈRE, M. W. A psycholinguistic approach to graphic language use. In: von TETZCHNER, S.; JENSEN, M. (Eds.) Augmentative and alternative communication: European perspectives. London: Whurr/San Diego: Singular, 1996, p. 153170.

VON TETZCHNER, S. Enunciado de múltiplos símbolos no desenvolvimento da linguagem gráfica. In: NUNES, L.R.O.P. (Org.) Favorecendo o desenvolvimento da comunicação em crianças e jovens com necessidades educacionais especiais. Rio de Janeiro: Dunya, 2003.

VON TETZCHNER, S.; DILLE, K.; JORGENSEN, K.K.; ORMHAUG, B.M.; OXHOLM, B.; WARME, R. From single signs to relational meanings. In: $8^{\text {th }}$ Biennial Conference of the International Society for Augmentative and Alternative Communication. Dublin, Irlanda, 1998 (8). 
GUARDA, N. S.; DELIBERATO, D.

VON TETZCHNER, S.; MARTINSEN, H. Introduction to sign teaching and the use of communication aids. London: Whurr, 1992.

VON TETZCHNER, S.; MARTINSEN, H. Words and strategies: Comunication with Young children who use aided language. In: VON TETZCHENER, S.; JENSEN, M.H. (Ed.) Augmentative and alternative communication: European perspectives (pp. 65-88), London: Whurr, 1996.

VON TETZCHNER, S.; MARTINSEN, H. Introdução à comunicação aumentativa e alternativa. Portugal: Editora Porto, $2^{\mathrm{a}}$ ed., 2000.

Recebido em 31/05/2006

Reformulado em 22/08/2006

Aprovado em 30/08/2006 